Review Article

\title{
Ezetimibe and Improving Cardiovascular Outcomes: Current Evidence and Perspectives
}

\author{
Akshyaya Pradhan (D), Monika Bhandari (iD, and Rishi Sethi \\ Department of Cardiology, King George's Medical University, Lucknow, Uttar Pradesh 226003, India \\ Correspondence should be addressed to Monika Bhandari; drmonikab@gmail.com
}

Received 12 February 2020; Accepted 11 May 2020; Published 28 June 2020

Academic Editor: Francesco Fedele

Copyright (C) 2020 Akshyaya Pradhan et al. This is an open access article distributed under the Creative Commons Attribution License, which permits unrestricted use, distribution, and reproduction in any medium, provided the original work is properly cited.

\begin{abstract}
Low-density lipoprotein lowering with statins has convincingly and consistently proven to reduce cardiovascular events in both primary and secondary prevention. However, despite high-dose statin therapy, residual cardiovascular risk remains and many patients also do not tolerate statins. Ezetimibe was initially projected as a frontline alternative to statin. It is an intestinal cholesterol absorption inhibitor with modest LDL lowering effects. But, major studies failed to demonstrate any beneficial effect of $\mathrm{CV}$ outcomes, and the drug was relegated to oblivion. IMPROVE-IT, a contemporary, large, and well-designed trial, unequivocally demonstrated reduction in CV outcomes with ezetimibe when added to statin therapy. The benefits are seen in both sexes, elderly, CKD, diabetes mellitus, and in patients with prior CABG. It also reduces biomarkers and induces plaque regression like statins. The drug has now established itself as an add-on therapy to statin when monotherapy fails to achieve LDL goals and when it is not tolerated. The combination therapy has excellent safety and efficacy record. It has now been endorsed by major guidelines too in management of dyslipidemia. Yes, ezetimibe can indeed improve cardiovascular outcomes!
\end{abstract}

\section{Introduction}

It is well known fact that deposition of LDL-C and cholesterol-rich Apo-B containing lipoproteins in the arterial walls is responsible for atherosclerosis. Atherosclerotic cardiovascular diseases (ASCVD include patients with acute coronary syndromes, prior myocardial infarction (MI), stable or unstable angina, history of past arterial revascularization, stroke, transient ischemic attack (TIA), or peripheral artery disease (PAD) including aortic aneurysm, all of atherosclerotic origin) are the major cause of death worldwide, so prevention of ASCVD by control of risk factors including hypercholesterolemia, diabetes, and hypertension is important to save lives. Plasma low-density lipoprotein cholesterol (LDL-C) is a measure of cholesterol mass carried by LDL particles. Mendelian studies and randomized control trials have consistently shown a loglinear relationship between absolute changes in plasma LDL$\mathrm{C}$ and the risk of ASCVD. Also, it has been revealed in
Mendelian studies that long-term exposure to low LDL-C lowers the risk for CV events.

1.1. LDL Lowering Reduces CVEvents. Positive correlation of LDL-C and Cardiovascular (CV) risk is demonstrated by various epidemiological studies, and this relationship even extends to low LDL-C levels $[1,2]$. We also know from genetic studies that an individual with lifetime exposure to high LDL-C as in heterozygous familial hypercholesterolemia is at high risk for premature atherosclerosis and cardiovascular disease [3]. On the contrary, individuals who have genetic mutations for low LDL-C have lower chances of atherosclerotic cardiovascular diseases (ASCVD) [4]. Statins are 3-hydroxy-3-methylglutaryl-coenzyme A (HMG-CoA) reductase inhibitors. A meta-analysis of 27 randomized trials involving 174,000 participants revealed that for every $\sim 40 \mathrm{mg} / \mathrm{dL}$ LDL-C reduction with statin therapy, the relative risk of major adverse cardiovascular events is reduced by 
$\sim 20-25 \%$, and all-cause mortality is reduced by $10 \%$. Intensification of statin regimens yield a $15 \%$ further reduction in major adverse cardiovascular events [5].

1.2. Residual Risk with Statin Therapy. A meta-analysis of major statin trials revealed that even after intensive statin therapy, there remains a residual risk of CV events. The 5year rate of major CV events was $22 \%$ among individuals with prior $\mathrm{CV}$ disease and $10 \%$ in those who did not have history of an established CV disease [6]. This residual risk may be due to lipid-related factors (high triglycerides and low high-density lipoprotein cholesterol) or nonlipid factors(inflammation). Hence, the search for nonstatin alternatives to reduce CV risk is imperative. Figure 1 depicts the approximate residual risk in various primary and secondary prevention trials of statin therapy. In the past decade, ezetimibe has emerged as a formidable adjunct to statins in $\mathrm{LDL}$ lowering and $\mathrm{CV}$ risk reduction.

\section{Ezetimibe: The Drug}

Ezetimibe is a cholesterol absorption inhibitor, which targets LDL-C uptake at the jejunal enterocyte brush border. The primary target of action is the cholesterol transport protein Nieman Pick C1-like 1 protein (NPC1L1P). The drug is safe and well-tolerated. Statins lower the LDL-C levels by $35 \%-$ $60 \%$. But, they are associated with compensatory increase in hepatic LDL-C receptor production and enhanced uptake of serum LDL-C into the liver. Simultaneously, there is also an increased intestinal absorption of LDL-C cholesterol [7]. Thus, simultaneous use of statins and inhibitors of intestinal LDL-C absorption can yield a cumulative reduction in LDL$\mathrm{C}$ in individuals with high residual LDL-C to reduce $\mathrm{CV}$ events [8]. The salient features of ezetimibe are summarized in Figure 2.

2.1. Ezetimibe: The Initial Experience Was Mixed. A positive impact of using ezetimibe on carotid atherosclerosis was observed in the Stop Atherosclerosis in Native Diabetics Study (SANDS, Table 1) [9]. A reduction in Carotid IntimaMedia Thickness (CIMT) was seen in patients treated with statin and ezetimibe combination or those who received aggressive LDL-C lowering treatment. In patients who were not able to meet LDL-C targets, in multivariate analysis, it was revealed that the change in CIMT was related to the degree of LDL-C reduction and independent of specific choice of lipid-lowering therapy. Further beneficial effects of combination therapy with ezetimibe were reported in the Vytorin on and Overall Arterial Rigidity (VYCTOR) study, in which the primary end point happened to be the change in CIMT [10]. In the ezetimibe and simvastatin in the Hypercholesterolemia Enhances Atherosclerosis Regression (ENHANCE) trial [11], despite the significant difference in LDL-C lowering ( $-55.6 \%$ vs. $-39.1 \%, P<0.01)$, there was no significant difference in the average of mean carotid and femoral IMT measurements after 2 years of treatment $(+0.0033 \mathrm{~mm}$ for placebo vs. $0.0182 \mathrm{~mm}$ for ezetimibe, $P=0.15)$. However, in the ARBITER 6 trial, there was insignificant reduction of CIMT with ezetimibe [12]. These negative results stood in contrast to the prior atorvastatin versus simvastatin on the Atherosclerosis Progression (ASAP) trial, in which high-dose treatment using atorvastatin $80 \mathrm{mg} /$ day in subjects with heterozygous $\mathrm{FH}$ resulted in a greater reduction in LDL-C as compared to treatment with moderate-dose simvastatin of $40 \mathrm{mg}$ /day [13]. This difference in LDL-C reduction was associated with regression of CIMT of $-0.031 \mathrm{~mm}$ in the atorvastatin group and progression of $+0.036 \mathrm{~mm}$ in the simvastatin group $(P=0.0001$ for between-group comparison).

The clinical efficacy of ezetimibe was first studied in the SEAS trial. This study involved 1873 patients of mild-tomoderate aortic stenosis who were randomized to either ezetimibe $10 \mathrm{mg} /$ day plus simvastatin $40 \mathrm{mg} /$ day or placebo [14]. Although LDL-C was significantly reduced by $61 \%$ as compared to placebo, there was no significant reduction in composite of primary end points of need for aortic valve surgery and cardiovascular events. But, there was a significant reduction in fatal and nonfatal MI by $41 \%$ [15].

2.2. SHARP Trial: Beginning of Windfall for Ezetimibe. In the SHARP trial, patients of chronic kidney disease (both with or without dialysis dependence) were randomized to simvastatin $20 \mathrm{mg}$ /day plus ezetimibe $10 \mathrm{mg}$ /day or placebo. A significant $17 \%$ reduction in major atherosclerotic events was seen in the ezetimibe group as compared to placebo $(P=0.0021)$ after 5 years of therapy. Again, risk reduction was proportional to the magnitude of LDL-C reduction. There was no excess risk of adverse events, including myopathy and rhabdomyolysis [16].

To sum up, ezetimibe demonstrated atherosclerosis regression in SANDS and VYCTOR, while cardiovascular benefit was established in SEAS and SHARP using combination therapy with it. But, the negative outcomes reported from ENHANCE and ARBITER 6 generated significant controversy and dampened the enthusiasm for the role of ezetimibe in the treatment of hypercholesterolemia.

\section{IMROVE-IT: The Game Changer}

Despite the initial favorable outcomes with ezetimibe and statin combination, due to the dismal outcomes of ENHANCE and ARBITER 6 trials, ezetimibe was relegated from guidelines and scientific advisories. But, in 2015, the IMProved Reduction of Outcomes: Vytorin Efficacy International Trial (IMPROVE-IT) trial sorted out all the controversies and emerged as a game changer for treating hypercholesterolemic patients whose LDL-C is not controlled despite high intensity statin therapy [17].

The IMPROVE-IT trial evaluated the effect of ezetimibe in combination with simvastatin, as compared to simvastatin alone, in stable patients with recent history of an acute coronary syndrome (ACS) with LDL cholesterol within the guideline-recommended limits. Patients of 50 years of age or more with history of ACS within past 10 days with an LDL-C range of $50-100 \mathrm{mg} / \mathrm{dl}$ on statin therapy or between $50-125 \mathrm{mg} / \mathrm{dl}$ if statin naïve were included in the study. 


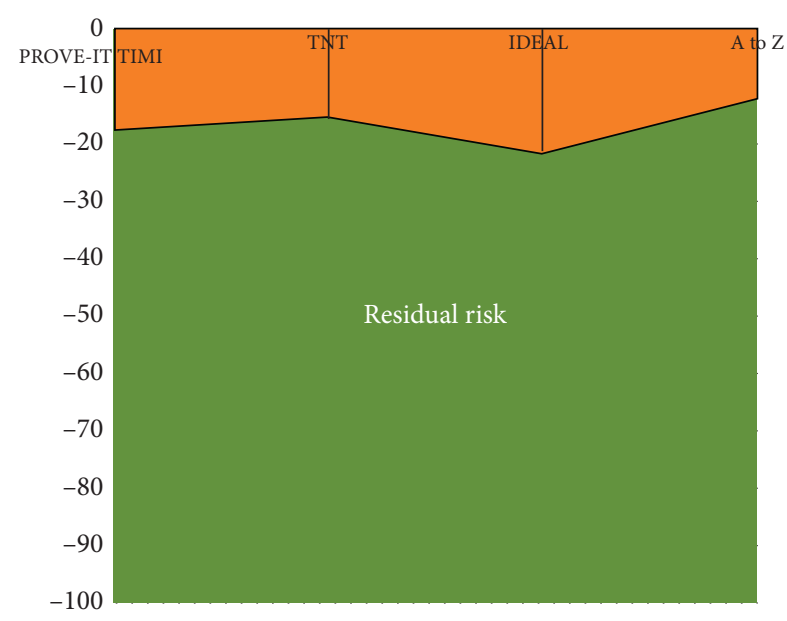

(a)

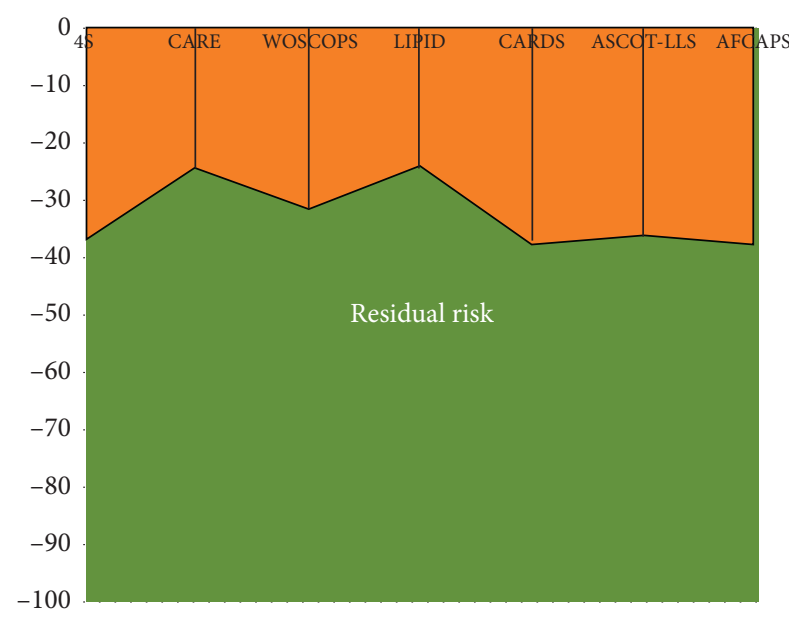

(b)

FIgURE 1: Residual risk in the large randomized statin trials for secondary (a) and primary prevention (b), respectively.

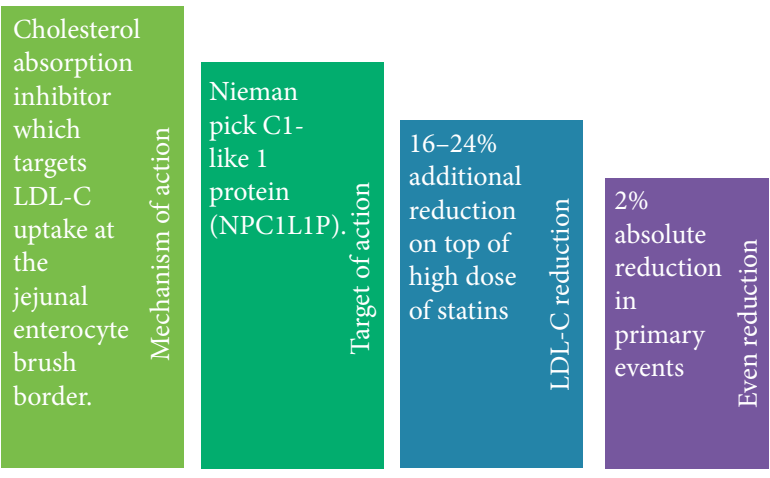

FIgURE 2: Salient features of ezetimibe.

Patients were excluded if they had a creatinine clearance $<30 \mathrm{ml} / \mathrm{min}$ or active liver disease or if they were planned for CABG. The primary efficacy end points of the study was a composite of death from cardiovascular death, a major coronary event (nonfatal MI, unstable angina (UA) requiring hospital admission, or coronary revascularization occurring at least 30 days after randomization), and nonfatal stroke. The key secondary efficacy end points were either of these three: a composite of death from any cause, major coronary event, and nonfatal stroke or a composite of death from CAD, nonfatal MI and urgent coronary revascularization $\geq 30$ days after randomization or a composite of death from CV causes, nonfatal MI, hospitalization for UA, all revascularization $\geq 30$ days after randomization and nonfatal stroke.

In this study, the average age of the study population was 64 years, $24 \%$ subjects were females, and history of diabetes mellitus was present in $27 \%$. About $88 \%$ patients had undergone coronary angiography, while $70 \%$ had received percutaneous coronary intervention during the index hospitalization. Only $34 \%$ were already on statins before the index event, and $77 \%$ received statin therapy during hospitalization. After 1 year of therapy, the mean LDL-C was
$69.9 \mathrm{mg} / \mathrm{dl}$ in the simvastatin group and $53.2 \mathrm{mg} / \mathrm{dl}$ in the simvastatin plus ezetimibe group representing $16.7 \mathrm{mg} / \mathrm{dl}$ (24\%) further reduction in LDL-C with the combination therapy. At 7 years, the rates for the primary end point were $32.7 \%$ in the simvastatin-ezetimibe group and $34.7 \%$ in the simvastatin monotherapy group (absolute risk reduction(ARR) of 2.0\%; hazard ratio (HR): 0.936 ; 95\% confidence interval (CI): 0.89 to $0.99 ; P=0.016)$. The rate of all 3 secondary end-points were also significantly reduced in simvastatin-ezetimibe group (Figure 3). The occurrence of side effects like derangement of LFT, gall bladder diseases, and muscle symptoms were similar in both the groups. The rate of discontinuation of therapy was $10.1 \%$ in the simvastatin monotherapy and $10.6 \%$ in the simvastatin-ezetimibe group. The benefits of ezetimibe combination to simvastatin were evident in all the subgroups especially in diabetics and those above 75 years of age. The number needed to treat (NNT) for the prevention of one primary end point event was 50 .

3.1. Ezetimibe in Diabetes Mellitus (DM). Diabetes mellitus increases the risk of coronary artery disease and the presence of DM in patient presenting with ACS portends poor outcomes [18]. However, interestingly, diabetic patients derive greater benefits compared to their nondiabetic counterparts.

In the prespecified subgroup analysis of IMPROVE-IT, DM was present in 4933 (27\%) patients of the study population [19]. Patients with DM were more likely to be female; were older; and had a history of prior MI or CABG. These were less likely to present with an ST-elevation MI $(P<0.001)$ as compared with patients without DM. These patients were more likely to be on guideline-supported therapies and were more likely to be on statins prior to the index event. There was an ARR of $5.5 \%$ (HR, 0.85 ; 95\% CI, 0.78-0.94) by combination therapy in diabetic patients at 7 years, while in nondiabetic patients, the ARR was only $0.7 \%$ (HR, 0.98; 95\% CI, 0.91-1.04; Pint $=0.02$ ). The NNT for primary end point event reduction was 38 as compared to 50 in overall population described 
TABle 1: Pivotal trials of ezetimibe.

\begin{tabular}{|c|c|c|c|c|c|}
\hline Trial & Year & $\begin{array}{l}\text { Number } \\
\text { of patients }\end{array}$ & Study population & Study design & Results \\
\hline SANDS & 2008 & 499 & $\begin{array}{c}\text { American-Indian men and } \\
\text { women aged } 40 \text { years or older } \\
\text { with type } 2 \text { diabetes and no } \\
\text { prior CVD events }\end{array}$ & $\begin{array}{c}\text { Randomized to aggressive (LDL- } \\
\mathrm{C}<70, \mathrm{SBP}<115 \mathrm{mmHg}) \\
(n=252) \text { vs. standard (LDL- } \\
\mathrm{C}<100, \mathrm{SBP}<130 \mathrm{mmHg}) \\
(n=247) \text { treatment }\end{array}$ & $\begin{array}{l}\text { CIMT regressed in the aggressive } \\
\text { group and increased in the standard } \\
\text { group }(-0.012 \mathrm{~mm} \text { vs. } 0.038 \mathrm{~mm} \text {; } \\
P<0.001) \text {; carotid arterial cross- } \\
\text { sectional area was also reduced } \\
(-0.02 \mathrm{~mm}(2) \text { vs. } 1.05 \mathrm{~mm}(2) ; \\
P<0.001)\end{array}$ \\
\hline ENHANCE & 2008 & 720 & $\begin{array}{l}\text { Patients of heterozygous } \mathrm{FH} \\
\text { were taken to see } \\
\text { atherosclerosis regression with } \\
\text { ezetimibe }\end{array}$ & $\begin{array}{l}\text { Simvastatin } 80 \mathrm{mg}(n=363) \text { or } \\
\text { simvastatin } 80 \mathrm{mg} \text { plus ezetimibe } \\
10 \mathrm{mg}(n=357)\end{array}$ & $\begin{array}{l}\text { Ezetimibe plus simvastatin did not } \\
\text { produce a significant reduction in } \\
\text { carotid IMT despite the further } \\
\text { reduction in LDL-C and hs-CRP } \\
\text { achieved with this drug }\end{array}$ \\
\hline ARBITER 6 & 2010 & 315 & $\begin{array}{l}\text { Patients of CAD/CAD } \\
\text { equivalent with LDL-C } \\
<100 \mathrm{mg} / \mathrm{dl} \text { and HDL-C } \\
<50 \mathrm{mg} / \mathrm{dl} \text { for men or } 55 \mathrm{mg} / \\
\mathrm{dl} \text { for women (on statin } \\
\text { treatment) for CIMT } \\
\text { progression }\end{array}$ & $\begin{array}{c}\text { Ezetimibe }(10 \mathrm{mg} / \text { day) or } \\
\text { extended-release niacin (target } \\
\text { dose, } 2,000 \mathrm{mg} / \text { day) }\end{array}$ & $\begin{array}{c}\text { Patients on niacin }(n=154) \text { had } \\
\text { significant regression in both mean } \\
\text { CIMT }(-0.0102 \pm 0.0026 \mathrm{~mm} ; \\
P<0.001) \text { and maximal CIMT } \\
(-0.0124 \pm 0.0036 \mathrm{~mm} ; P=0.001) \\
\text { Ezetimibe }(n=161) \text { did not reduce } \\
\text { mean CIMT }(-0.0016 \pm 0.0024 \mathrm{~mm} \text {; } \\
P=0.88) \text { or maximal CIMT } \\
(-0.0005 \pm 0.0029 \mathrm{~mm} ; P=0.88) \\
\text { compared with baseline }\end{array}$ \\
\hline VYCTOR & 2009 & 90 & $\begin{array}{l}\text { To see effect aggressive lipid } \\
\text { lowering on CIMT, LDL-C } \\
\text { and hs-CRP in high-risk } \\
\text { patients }\end{array}$ & $\begin{array}{l}90 \text { high-risk CAD were allocated } \\
\text { to } 3 \text { groups: pravastatin } 40 \mathrm{mg} \text {, } \\
\text { simvastatin } 40 \mathrm{mg} \text {, and } \\
\text { simvastatin } 20 \mathrm{mg} \text { with ezetimibe } \\
10 \mathrm{mg}\end{array}$ & $\begin{array}{l}\text { After } 1 \text { year of therapy, a significant } \\
\text { reduction in LDL-C to a mean level of } \\
45-48 \mathrm{mg} / \mathrm{dL} \text { was seen with a } \\
\text { significant reduction in all three } \\
\text { groups and CIMT values were } \\
0.93 \pm 0.13 \mathrm{~mm}, 0.90 \pm 0.11 \mathrm{~mm} \text {, and } \\
0.92 \pm 0.01 \mathrm{~mm} \text { for groups } 1,2 \text {, and } 3 \text {, } \\
\text { respectively }\end{array}$ \\
\hline SHARP & & 9270 & 9270 patients with CKD & $\begin{array}{l}\text { Simvastatin/ezetimibe } 20 / 10 \text { vs. } \\
\text { placebo }\end{array}$ & $\begin{array}{l}\text { LDL-C lowering with combination } \\
\text { therapy reduced major } \\
\text { atherosclerotic events in a wide range } \\
\text { of CKD patients }\end{array}$ \\
\hline SEAS & 2008 & 1873 & Patients of asymptomatic AS & $\begin{array}{c}\text { Double blind randomized control } \\
\text { trial between simvastatin/ } \\
\text { ezetimibe } 40 / 10 \text { vs. simvastatin } \\
40 \mathrm{mg} \text { on cardiovascular } \\
\text { outcomes }\end{array}$ & $\begin{array}{l}\text { No effect on AS progression with } \\
\text { LDL-C lowering. There were fewer } \\
\text { ischemic cardiovascular events in the } \\
\text { combination therapy }\end{array}$ \\
\hline $\begin{array}{l}\text { IMPROVE- } \\
\text { IT }\end{array}$ & 2010 & 18144 & High-risk post-ACS patients & $\begin{array}{c}\text { Randomized to simvastatin/ } \\
\text { ezetimibe } 40 / 10 \mathrm{vs} \text {. simvastatin } \\
10 \mathrm{mg}\end{array}$ & $\begin{array}{l}\text { Simvastatin/ezetimibe combination } \\
\text { superior to simvastatin monotherapy } \\
\text { in reducing events ( } 32.7 \text { vs. } 34.7 \% \text {, } \\
\qquad P=0.016)\end{array}$ \\
\hline
\end{tabular}

above. The greatest relative reductions were due to reduction in MI (24\%) and ischemic stroke (39\%) in diabetics. There were no differences in safety outcomes in two treatment arms regardless of DM. More importantly, when stratified according to the TIMI risk score, all diabetics irrespective of the risk zone tend to derived benefit, whereas in nondiabetics, only those with high risk had benefit from the ezetimibe combination reiterating $\mathrm{DM}$ as a risk modifier.

3.2. Ezetimibe and Elderly. In patients presenting with acute coronary syndromes, increasing age is an important factor for adverse prognosis. Although individuals with age $>75$ years of age represent only $<6 \%$ of total ACS patients, up to $65 \%$ of ACS mortality is seen this cohort $[20,21]$. However, use of high dose statin therapy leads to significant adverse effects in elderly. Thus, the combination of ezetimibe to statin might achieve target LDL-C among them without increasing the adverse effects.

It was found in the IMPROVE-IT trial that the combination therapy significantly reduced LDL levels in patients $>75$ years of age and resulted in risk reduction. The reduction in absolute risk of primary end points in them was higher than young individuals, and the combination was also well-tolerated [22].

3.3. Ezetimibe in Chronic Kidney Disease (CKD). Individuals with $\mathrm{CKD}$ are at heightened risk for cardiovascular mortality, and eGFR is an independent and robust 


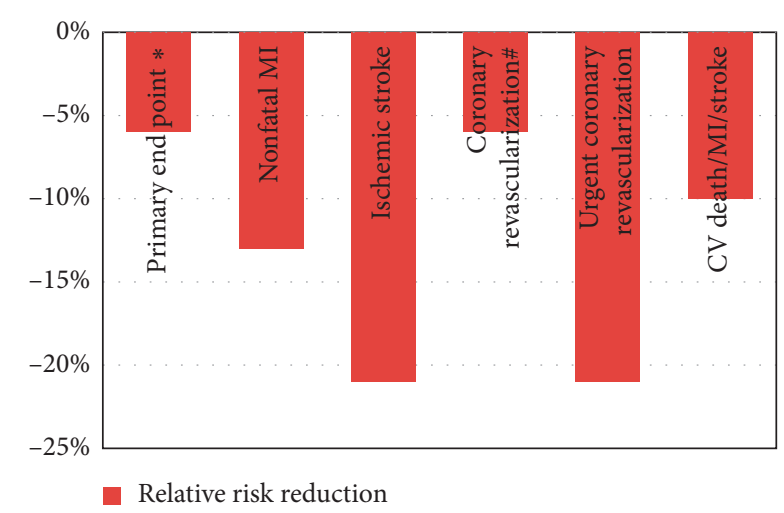

FIgURE 3: Clinical benefits achieved in the IMPROVE-IT trial ( ${ }^{*}$ primary end point was a combination of $\mathrm{CV}$ death/major $\mathrm{CV}$ event and nonfatal stroke; \#nonsignificant. There was no difference in CV death and unstable angina).

predictor of risk [23]. A meta-analysis of 14 statin trials in CKD showed a trend towards reduction in occurrence of first CV event through LDL lowering. However, this benefit decreases as GFR declines further [6].

SHARP was the first trial to show that the major $\mathrm{CV}$ events were safely reduced by simvastatin and ezetimibe combination in a wide range of CKD patients [16]. Based on this strong results from this trial, 2013 ACC/AHA guidelines endorsed the use of ezetimibe patients with eGFR $<60 \mathrm{ml} /$ min [24]. Data from the IMPROVE-IT study mirrored similar findings [25]. Out of a total 18,144 patients, 3791 had eGFR $<60 \mathrm{ml} / \mathrm{min}$. Such patients were more frequently elderly, female, and nonsmoker with additional comorbidities. Addition of ezetimibe improved lipid parameters across all eGFR subgroups. In both the groups, the event rates were higher with lower eGFR. However, the addition of ezetimibe over statins produced a $12 \%$ and $13 \%$ risk reduction in patients with baseline eGFR $<60 \mathrm{ml} / \mathrm{min}$ and $<45 \mathrm{ml} / \mathrm{min}$, respectively.

3.4. Ezetimibe and Plaque Regression on Imaging. Plaque burden is an important surrogate marker of future $\mathrm{CV}$ events. Various imaging techniques like IVUS are available to measure plaque volume. Studies have shown that statins modify the natural history of CAD by decreasing plaque progression and may even result in atheroma regression. Although it was evident from the IMPROVE-IT trial that the addition of ezetimibe to statins further lowers LDL-C and, hence, reduces future events especially after ACS, but whether it has any effect on atheromatous plaque was not known.

In the PRECISE-IVUS trial, it was studied that whether aggressive lipid lowering by adding ezetimibe to standard statin therapy has any effect on coronary atherosclerosis [26]. When observed by IVUS examination, an individual who received combination therapy had significant plaque regression (assessed by percentage atheroma volume) compared to monotherapy ( $78 \%$ vs. $58 \%$; $P=0.04)$. Subsequently, in a metanalysis of 6 trials of statin and ezetimibe combination therapy, it was found that the combination therapy resulted in more plaque regression [27]. The decline in total atheroma volume from baseline to follow-up was of $-3.71 \mathrm{~mm}^{3}$ (mean difference, 95\% CI-25.98 to 21.44, $P=0.001)$, while the percent atheroma volume attenuation stood at a mean of $-0.77 \%(-1.68$ to $-0.14, P=0.10)$.

3.5. Ezetimibe in Post-CABG Patients. Patients with prior $\mathrm{CABG}$ are at high risk for recurrent ischemic events as they have extensive atherosclerotic disease. Also, when these patients present with ACS, the prognosis is quite poor [28]. Thus, these patients should receive the best drug treatment for attenuating the atherosclerotic burden in order to improve their prognosis.

In a subanalysis of the IMPROVE-IT trial, it was found that patients of ACS who had prior CABG had poor prognosis having multiple risk factors like older age, prior MI, DM, hypertension, PAD, and prior stroke [29]. Secondly, there was enhanced benefit on adding ezetimibe to statin in such patients which was beyond LDL reduction, possibly due to some pleotropic effects such as inhibition of vascular smooth muscle proliferation, sterol reduction, and antioxidant effects.

3.6. Ezetimibe and Gender. LDL lowering by statins has been proven to decrease cardiovascular outcomes in both men and women alike [30]. But, unfortunately there is an inertia among physicians for prescribing statin therapy in females [31]. The role of nonstatin drugs in reducing CV outcomes in females is less clear.

In a prespecified subgroup analysis of IMPROVE-IT, $24 \%$ of participants were females [32]. At the study completion, LDL-c was lowered comparably in both the groups (16.7 mg/dl\& $16.4 \mathrm{mg} / \mathrm{dl}$ in males and females, respectively). Interestingly, despite a similar LDL reduction females had numerically more reduction of primary end point (12\% vs. $5 \%$ relative risk reduction in men and women, respectively). Although, the results did not reach statistical significance, it will be worthy to note that benefits were primarily driven by amelioration of MI.

3.7. Ezetimibe and Recurrent $C V$ Events. In the IMPROVEIT trial, there were a total of 9,545 primary end point events, and out of them, 56\% were first events and rest $44 \%$ were subsequent events which were not included in the primary analysis [33]. By virtue of a long follow-up period, up to 13 percent of patients experienced recurrent events in the study. The proportion of unstable angina, stroke, and CV death were not different between first and recurrent episodes. However, there were lesser MI's and higher revascularization in subsequent events as compared to index events.

Ezetimibe-based combination therapy not only reduced first CV events but also second, third, and subsequent events. The additional event reduction in the combination arm with first and recurrent events was -170 (6.2\%) and -241 (11.2\%), respectively. For every 100 patients treated with ezetimibe- 
TABLE 2: Number of adverse CV events prevented with ezetimibe when added over and above statins (data from the IMPROVE-IT study).

\begin{tabular}{lc}
\hline Event type & Numbers halted $^{*}$ \\
\hline Combination of CVD, nonfatal MI,UA, revascularization, and nonfatal stroke & 11 \\
Nonfatal MI & 5 \\
Nonfatal stroke & 2 \\
Revascularization & 4 \\
\hline
\end{tabular}

${ }^{*}$ For 100 patients treated for 10 years (CVD- cardiovascular death; UA- unstable angina; MI- myocardial infarction).

TABLE 3: Graded risk reduction by ezetimibe therapy with absolute number of biomarkers elevated in substudy of the IMPROVE-IT trial. Modified from Qamar et al. [36] (NNT- number needed to treat).

\begin{tabular}{lccc}
\hline Risk category & Number of biomarkers elevated & Absolute risk difference (\%) & NNT \\
\hline High risk & $>3$ & -7.3 & 14 \\
Intermediate risk & $1-2$ & -4.4 & 23 \\
Low risk & 0 & +3.0 & - \\
\hline
\end{tabular}

based combination therapy for 10 years, 5 nonfatal MI, 4 revascularizations, and 2 nonfatal strokes are prevented. No $\mathrm{CV}$ death and unstable angina events are prevented. Hence, a composite of 11 primary end point events are prevented (Table 2).

3.8. Biomarkers and Risk Reduction by Ezetimibe. A multimarker strategy has been shown to be useful for risk stratification and prognosis in ACS patients [34]. Clinical markers have been used to triage patients who are at the highest risk and benefit from the addition of ezetimibe therapy [35]. Additionally, the role of biomarkers in the post-ACS scenario for utilization of ezetimibe therapy has been studied by Qamar et al. [36]. In a subanalysis of the IMPROVE-IT trial, high-sensitivity troponin T, $N$-terminal pro-B-type natriuretic peptide, growth-differentiation factor-15, and high-sensitivity C-reactive protein were estimated in 7,195 patients after 1 month of ACS. Independent associations of each these biomarkers were seen with outcomes of death/MI/stroke and CV death/heart failure. It was also demonstrated in that patients deemed to be at higher risk based on the elevation of biomarkers, the ezetimibe combination therapy was associated with greater absolute risk reduction. A graded response for absolute benefit with ezetimibe was seen with the number of biomarkers elevated (See Table 3). The number needed to treat (NNT) in the cohort with 3 or more biomarker positive was only 14 .

3.9. Ezetimibe in Statin-Intolerant Patients. Both European and American guidelines recommend statins as first-line lipid-lowering therapy in patients with ASCVD. However, in individuals who have uncontrolled LDL with statins and who are intolerant to statins, there is an emerging consensus on the role of using ezetimibe or proprotein convertase subtilsin/kexin type 9 (PCSK9) inhibitors [37].

Statin intolerance is not uncommon, and according to the observational studies, approximately $25 \%$ of the patients have some degree of statin intolerance which may lead to nonadherence [38]. Nonadherence to statin is not benign and increases the risk of recurrent MI and coronary heart disease events [39]. In a simulation analysis by Canon et al., it was found that the use of ezetimibe is increased by $8 \%$ while that of PCSK9 inhibitors by $7 \%$ in patients having partial or full statin intolerance (assumed at 10\%) [40]. However, PCSK9 inhibitors have cost issues, and it may itself lead to drug discontinuation, so ezetimibe is a first-line option in such patients being an effective lipid-lowering drug with low cost [41].

3.10. Ezetimibe and Drug Adherence. Premature discontinuation of lipid-lowering therapies is a major impediment in achieving secondary prevention goals after acute coronary syndromes [42]. For statin therapy, on long-term follow-up, the observed discontinuation rates may be as high as 50\% [43].

In the IMPROVE-IT trial, the medication discontinuation rate was slightly higher in the simvastatin monotherapy arm vis-a-vis simvastatin plus ezetimibe combination arm (52\% vs. $49.8 \% ; P=0.049$ ).Factors favoring drug discontinuation were smoking, prior revascularization, hypertension, unstable angina, female sex, nonwhite race, and US location [44]. The I-ROSETTE study results resonated similar findings [45]. In the study, the combination of ezetimibe to rosuvastatin significantly improved lipid profile (LDL reduced by 50\%) in hypercholesterolemia patients without any extra side effects. In fact, the combination was better tolerated as compared to an equivalent dose of rosuvastatin due to different metabolic route of action of the two drugs [45]. So, we can reasonably infer that the combination of statin and ezetimibe has got comparable safety and tolerability as statin monotherapy.

\section{Guideline Track}

According to 2018 ACC/AHA lipid guidelines, for patients with clinical ASCVD who are deemed to be at high risk, an LDL-C goal of $<70 \mathrm{mg} / \mathrm{dl}$ or $>50 \%$ reduction in LDL-C from baseline is recommended [46]. However, the latest ESC guidelines for the management of dyslipidemia recommends LDL-C reduction of $>50 \%$ from baseline or LDL-C $<55 \mathrm{mg} /$ $\mathrm{dl}$ in them for secondary prevention [47]. In either case, if these goals are not achieved by maximum tolerated doses of 


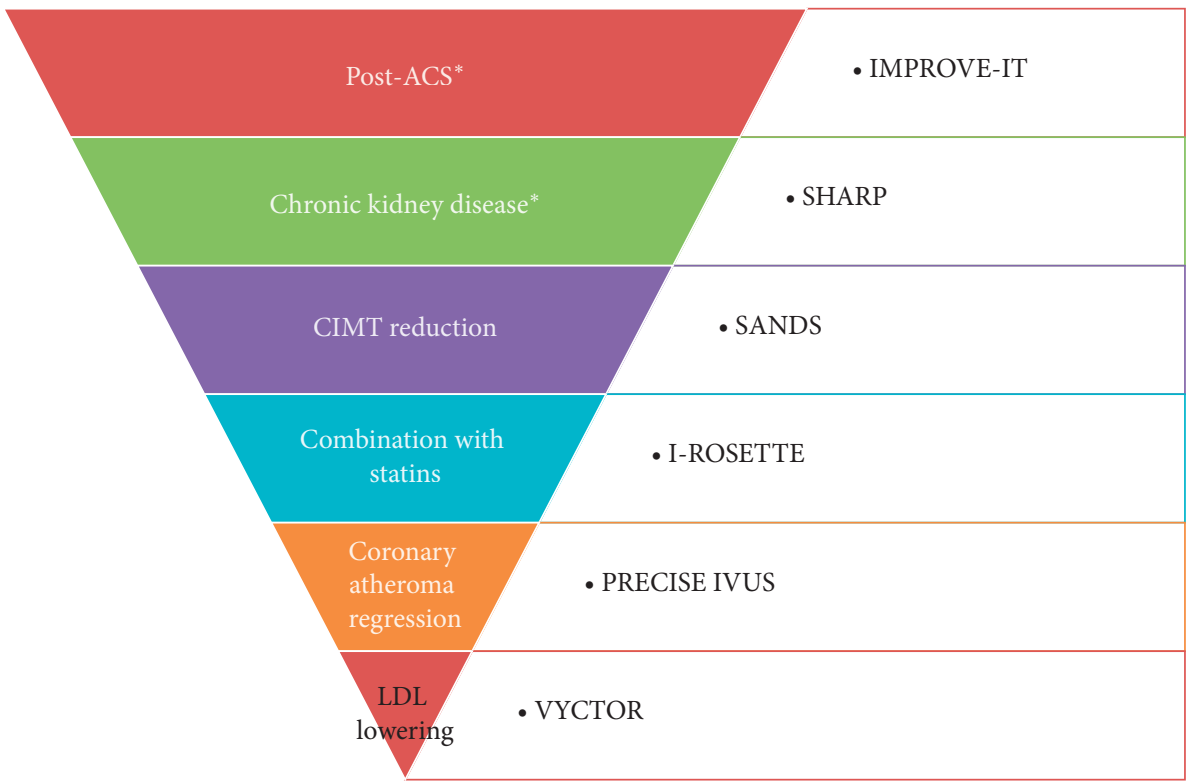

FIgURE 4: Various clinical scenarios and the corresponding studies where ezetimibe has been shown to be useful. The trials are arranged in a declining order of sample size with the maximum in IMROVE-IT and minimum in VYCTOR. * Cardiovascular outcome trials (ACS- acute coronary syndrome; CIMT- carotid intima medial thickness).

statins, addition of ezetimibe is a class IIa recommendation by the ACC/AHA guidelines, while the ESC guidlelines suggest it is a Class I recommendation to add the drug.

\section{Summary}

LDL-C has a pivotal role in the pathogenesis of atherosclerosis and ASCVD. Statins are the primary and most important hypolipidemic agents which reduce LDL along with reduction in future CV events. However, many patients are not able to tolerate high statin doses or have uncontrolled LDL-C even with maximally tolerated doses leading to residual CV risk. Ezetimibe is a cholesterol absorption inhibitor with potent cholesterol lowering effects. As an individual agent, it failed to make an impact initially. The IMPROVE-IT was the game-changing study which pitchforked the drug into limelight. The combination of ezetimibe and statin was found to be effective in producing additional LDL-C reduction on top of statins and reduction of CV events as well. The drug has been effective in a wide range of patient profile too (Figure 4). Above all, the combination is safe and well-tolerated owing to a different mechanism of action on metabolic pathways. The drug has now found a widespread acceptability as an add-on therapy, and the latest guidelines recommend adding ezetimibe if LDL-C targets are not met with statins and there is a residual CV risk.

\section{Conflicts of Interest}

The authors declare that they have no conflicts of interest.

\section{References}

[1] Z. Chen, R. Peto, R. Collins, S. Macmahon, J. Lu, and W. Li, "Serum cholesterol concentration and coronary heart disease in population with low cholesterol concentrations," $B M J$, vol. 303, no. 6797, pp. 276-282, 1991.

[2] J. Stamler, O. Vaccaro, J. D. Neaton, and D. Wentworth, "Diabetes, other risk factors, and 12-yr cardiovascular mortality for men screened in the multiple risk factor intervention trial," Diabetes Care, vol. 16, no. 2, pp. 434-444, 1993.

[3] M. A. Austin, C. M. Hutter, R. L. Zimmern, and S. E. Humphries, "Familial hypercholesterolemia and coronary heart disease: a HuGE association review," American Journal of Epidemiology, vol. 160, no. 5, pp. 421-429, 2004.

[4] B. A. Ference, W. Yoo, I. Alesh et al., "Effect of long-term exposure to lower low-density lipoprotein cholesterol beginning early in life on the risk of coronary heart disease: a Mendelian randomization analysis," Journal of the American College of Cardiology, vol. 60, no. 25, pp. 2631-2639, 2012.

[5] B. Mihaylova, J. Emberson, L. Blackwell et al., "The effects of lowering LDL cholesterol with statin therapy in people at low risk of vascular disease: meta-analysis of individual data from 27 randomized trials," The Lancet, vol. 380, no. 9841, pp. 581-590, 2012.

[6] C. Baigent, A. Keech, and P. M. Kearney, "Efficacy and safety of cholesterol-lowering treatment: prospective meta-analysis of data from 90,056 participants in 14 randomized trials of statins," The Lancet, vol. 366, no. 9493, pp. 1267-1278, 2005.

[7] M. W. Huff and J. R. Burnett, "3-hydroxy-3-methylglutaryl coenzyme A reductase inhibitors and hepatic apolipoprotein B secretion," Current Opinion in Lipidology, vol. 8, no. 3, pp. 138-145, 1997.

[8] J. R. Guyton, "Combination regimens with statin, niacin, and intestinally active LDL-lowering drugs: alternatives to highdose statin therapy?" Current Opinion in Lipidology, vol. 21, no. 4, pp. 372-377, 2010.

[9] B. V. Howard, M. J. Roman, R. B. Devereux et al., "Effect of lower targets for blood pressure and LDL cholesterol on atherosclerosis in diabetes: the SANDS randomized trial," JAMA, vol. 299, no. 14, pp. 1678-1689, 2008.

[10] A. Meaney, G. Ceballos, J. Asbun et al., "The vytorin on carotid intima-media thickness and overall arterial rigidity 
(VYCTOR) study," The Journal of Clinical Pharmacology, vol. 49, no. 7, pp. 838-847, 2009.

[11] P. P. Toth and K. C. Maki, "A commentary on the implications of the ENHANCE (ezetimibe and simvastatin in hypercholesterolemia Enhances atherosclerosis regression) trial: should ezetimibe move to the "back of the line" as a therapy for dyslipidemia?" Journal of Clinical Lipidology, vol. 2, no. 5, pp. 313-317, 2008.

[12] A. J. Taylor, T. C. Villines, E. J. Stanek et al., "Extended-release niacin or ezetimibe and carotid intima-media thickness," New England Journal of Medicine, vol. 361, no. 22, pp. 2113-2122, 2009.

[13] T. Smilde, S. van Wissen, H. Awollersheim, M. Trip, J. Kastelein, and A. Stalenhoef, "Effect of aggressive versus conventional lipid lowering on atherosclerosis progression in familial hypercholesterolemia (ASAP): a prospective, randomised, double-blind trial," The Lancet, vol. 357, no. 9256, pp. 577-581, 2001.

[14] A. B. Rossebø, T. R. Pedersen, K. Boman et al., "Intensive lipid lowering with simvastatin and ezetimibe in aortic stenosis," New England Journal of Medicine, vol. 359, no. 13, pp. 1343-1356, 2008.

[15] I. Holme, K. Boman, P. Brudi et al., "Observed and predicted reduction of ischemic cardiovascular events in the simvastatin and ezetimibe in aortic stenosis trial," The American Journal of Cardiology, vol. 105, no. 12, pp. 1802-1808, 2010.

[16] C. Baigent, M. J. Landray, C. Reith et al., "The effects of lowering LDL cholesterol with simvastatin plus ezetimibe in patients with chronic kidney disease (study of heart and renal protection): a randomised placebo-controlled trial," The Lancet, vol. 377, no. 9784, pp. 2181-2192, 2011.

[17] C. P. Cannon, M. A. Blazing, R. P. Giugliano et al., "Ezetimibe added to statin therapy after acute coronary syndromes," New England Journal of Medicine, vol. 372, no. 25, pp. 2387-2397, 2015.

[18] S. M. Donahoe, G. C. Stewart, C. H. McCabe et al., "Diabetes and mortality following acute coronary syndromes," JAMA, vol. 298, no. 7, pp. 765-775, 2007.

[19] R. P. Giugliano, C. P. Cannon, M. A. Blazing et al., "Benefit of adding ezetimibe to statin therapy on cardiovascular outcomes and safety in patients with versus without diabetes mellitus," Circulation, vol. 137, no. 15, pp. 1571-1582, 2018.

[20] A. Vezum, M. Makdisse, F. Spencer et al., "GRACE investigators. Impact of age on management and outcome of acute coronary syndrome: observations from the global registry of acute coronary events (GRACE)," American Heart Journal, vol. 149, no. 1, pp. 67-73, 2005.

[21] D. Mozaffarian, E. J. Benjamin, A. S. Go et al., "Writing group members; American heart association statistics committee; stroke statistics subcommittee. heart disease and stroke statistics-2016 update: a report from the american heart association," Circulation, vol. 133, no. 4, pp. e38-e360, 2016.

[22] R. G. Bach, C. P. Cannon, R. P. Giugliano et al., "Effect of simvastatin-ezetimibe compared with simvastatin monotherapy after acute coronary syndrome among patients 75 years or older," JAMA Cardiology, vol. 4, no. 9, pp. 846-854, 2019.

[23] A. S. Go, G. M. Chertow, D. Fan, C. E. McCulloch, and C.-Y. Hsu, "Chronic kidney disease and the risks of death, cardiovascular events, and hospitalization," New England Journal of Medicine, vol. 351, no. 13, pp. 1296-1305, 2004.

[24] N. J. Stone, J. G. Robinson, A. H. Lichtenstein et al., "American college of cardiology/american heart association task force on practice guidelines: 2013 ACC/AHA guideline on the treatment of blood cholesterol to reduce atherosclerotic cardiovascular risk in adults: a report of the american college of cardiology/American heart association task force on practice guidelines," Circulation, vol. 129, no. 2, pp. S1-S45, 2014.

[25] J. W. Stanifer, D. M. Charytan, J. White et al., "Benefit of ezetimibe added to simvastatin in reduced kidney function," Journal of the American Society of Nephrology, vol. 28, no. 10, pp. 3034-3043, 2017.

[26] K. Tsujita, S. Sugiyama, H. Sumida et al., "Impact of dual lipidlowering strategy with ezetimibe and atorvastatin on coronary plaque regression in patients with percutaneous coronary intervention," Journal of the American College of Cardiology, vol. 66, no. 5, pp. 495-507, 2015.

[27] S. Mirzaee, P. M. Thein, J. Nogic, N. Nerlekar, A. Nasis, and A. J. Brown, "The effect of combined ezetimibe and statin therapy versus statin therapy alone on coronary plaque volume assessed by intravascular ultrasound: a systematic review and meta-analysis," Journal of Clinical Lipidology, vol. 12, no. 5, pp. 1133-1140, 2018.

[28] E. Nikolsky, B. T. McLaurin, D. A. Cox et al., "Outcomes of patients with prior coronary artery bypass grafting and acute coronary syndromes," JACC: Cardiovascular Interventions, vol. 5, no. 9, pp. 919-926, 2012.

[29] A. Eisen, C. P. Cannon, M. A. Blazing et al., "The benefit of adding ezetimibe to statin therapy in patients with prior coronary artery bypass graft surgery and acute coronary syndrome in the IMPROVE-IT trial," European Heart Journal, vol. 37, no. 48, pp. 3576-3584, 2016.

[30] W. J. Kostis, J. Q. Cheng, J. M. Dobrzynski, J. Cabrera, and J. B. Kostis, "Meta-analysis of statin effects in women versus men," Journal of the American College of Cardiology, vol. 59, no. 6, pp. 572-582, 2012.

[31] S. Poon, S. G. Goodman, R. T. Yan et al., "Bridging the gender gap: insights from a contemporary analysis of sex-related differences in the treatment and outcomes of patients with acute coronary syndromes," American Heart Journal, vol. 163, no. 1, pp. 66-73, 2012.

[32] E. T. Kato, C. P. Cannon, M. A. Blazing et al., "Efficacy and safety of adding ezetimibe to statin therapy among women and men: insight from IMPROVE-IT (improved reduction of outcomes: vytorin efficacy international trial)," Journal American Heart Association, vol. 6, no. 11, Article ID e006901, 2017.

[33] S. A. Murphy, C. P. Cannon, M. A. Blazing et al., "Reduction in total cardiovascular events with ezetimibe/simvastatin post-acute coronary syndrome," Journal of the American College of Cardiology, vol. 67, no. 4, pp. 353-361, 2016.

[34] M. L. O’Donoghue, D. A. Morrow, C. P. Cannon et al., "Multimarker risk stratification in patients with acute myocardial infarction," Journal American Heart Association, vol. 5, no. 5, Article ID e002586, 2016.

[35] E. A. Bohula, D. A. Morrow, R. P. Giugliano et al., "Atherothrombotic risk stratification and ezetimibe for secondary prevention," Journal of the American College of Cardiology, vol. 69, no. 8, pp. 911-921, 2017.

[36] A. Qamar, R. P. Giugliano, E. A. Bohula et al., "Biomarkers and clinical cardiovascular outcomes with ezetimibe in the IMPROVE-IT trial," Journal of the American College of Cardiology, vol. 74, no. 8, pp. 1057-1068, 2019.

[37] D. M. Lloyd-Jones, P. B. Morris, C. M. Ballantyne et al., "2017 focused update of the 2016 acc expert consensus decision pathway on the role of non-statin therapies for ldl-cholesterol lowering in the management of atherosclerotic cardiovascular 
disease risk," Journal of the American College of Cardiology, vol. 70, no. 14, pp. 1785-1822, 2017.

[38] M. Banach, M. Rizzo, P. P. Toth et al., "Position paper statin intolerance-an attempt at a unified definition. Position paper from an international lipid expert panel," Archives of Medical Science, vol. 1, pp. 1-23, 2015.

[39] M.-C. Serban, L. D. Colantonio, A. D. Manthripragada et al., "Statin intolerance and risk of coronary heart events and allcause mortality following myocardial infarction," Journal of the American College of Cardiology, vol. 69, no. 11, pp. 1386-1395, 2017.

[40] C. P. Cannon, R. J. Sanchez, A. C. Klimchak et al., "Simulation of the impact of statin intolerance on the need for ezetimibe and/or proprotein convertase subtilisin/kexin type 9 inhibitor for meeting low-density lipoprotein cholesterol goals in a population with atherosclerotic cardiovascular disease," The American Journal of Cardiology, vol. 123, no. 8, pp. 1202-1207, 2019.

[41] D. M. Lloyd-Jones, P. B. Morris, C. M. Ballantyne et al., “2016 ACC expert consensus decision pathway on the role of nonstatin therapies for LDL-cholesterol lowering in the management of atherosclerotic cardiovascular disease risk," Journal of the American College of Cardiology, vol. 68, no. 1, pp. 92-125, 2016.

[42] R. Mathews, T. Y. Wang, E. Honeycutt et al., "Persistence with secondary prevention medications after acute myocardial infarction: insights from the TRANSLATE-ACS study," American Heart Journal, vol. 170, no. 1, pp. 62-69, 2015.

[43] J. J. Ellis, S. R. Erickson, J. G. Stevenson, S. J. Bernstein, R. A. Stiles, and A. M. Fendrick, "Suboptimal statin adherence and discontinuation in primary and secondary prevention populations," Journal of General Internal Medicine, vol. 19, no. 6, pp. 638-645, 2004.

[44] A. M. Navar, M. T. Roe, J. A. White et al., "Medication discontinuation in the IMPROVE-IT trial," Circulation: Cardiovascular Quality and Outcomes, vol. 12, no. 1, Article ID e005041, 2019.

[45] S. J. Hong, H. S. Jeong, J. C. Ahn et al., "A phase III, multicenter, randomized, double-blind, active comparator clinical trial to compare the efficacy and safety of combination therapy with ezetimibe and rosuvastatin versus rosuvastatin monotherapy in patients with hypercholesterolemia: I-ROSETTE (ildong rosuvastatin \& ezetimibe for hypercholesterolemia) randomized controlled trial," Clinical Therapeutics, vol. 40, no. 2, pp. 226-241, 2018.

[46] F. Mach, C. Baigent, A. L. Catapano et al., "2019 ESC/EAS Guidelines for the management of dyslipidaemias: lipid modification to reduce cardiovascular risk-the task force for the management of dyslipidemias of the European society of cardiology (ESC) and the European atherosclerosis society (EAS)," European Heart Journal, vol. 41, no. 1, pp. 1-78, 2019.

[47] S. M. Grundy, N. J. Stone, A. L. Bailey et al., "2018 ACC/AHA/ AACVPR/AAPA/ABC/ACPM/ADA/AGS/APhA/ASPC/

NLA/PCNA guideline on the management of blood cholesterol: a report of the american college of cardiology foundation/american heart association task force on clinical practice guidelines," Journal of the American College of Cardiology, vol. 73, no. 24, pp. 3168-3209, 2018. 